\title{
Identification of low-flow parameters a using hydrological model in selected mountainous basins in Japan
}

\author{
KAZUMASA FUJIMURA ${ }^{1}$, YOSHIHIKO ISERI ${ }^{2}$, SHINJIRO KANAE ${ }^{2} \&$ \\ MASAHIRO MURAKAMI ${ }^{3}$ \\ 1 School of Science and Engineering, Meisei University, 2-1-1 Hodokubo, Hino, Tokyo 191-8506, Japan \\ fujimura@ar.meisei-u.ac.jp \\ 2 Department of Civil Engineering, Graduate School of Science and Engineering, Tokyo Institute of Technology, 2-12-1 \\ Ookayama, Meguro-ku, Tokyo 152-8550, Japan \\ 3 School of Environmental Science and Engineering, Kochi University of Technology, 185 Miyanokuchi, Tosayamada, \\ Kami-city, Kochi 782-8502, Japan
}

\begin{abstract}
Accurate estimation of the low-flow discharge is very important in evaluating the impact of climate change on water resources. This study focuses on the storage-discharge equation and the optimal parameters of the low flow. In order to investigate the sensitivity of the two parameters in the process of the calculation of low flow, we prepared 19900 sets of the two parameters in the storage-discharge equation and carried out hydrological analysis using the hourly hydrological model presented by Fujimura et al. (2012). The study basins are the Sameura Dam basin (SAME basin) located in western Japan which has variability of rainfall, and the Shirakawa Dam basin (SIRA basin) located in a region of heavy snowfall in eastern Japan. The period of available hydrological data is 20 years for the SAME basin and 10 years for the SIRA basin. The results suggest that the optimal combination of two parameters can be identified by exponential equations. This study also estimates the annual water balance for the two basins based on hydrological analysis using the optimal parameters in the storage-discharge equation of low flow.
\end{abstract}

Key words low-flow; storage-discharge exponential function; optimal parameter; sensitivity analysis; hydrological analysis

\section{INTRODUCTION}

In Japan, about $70 \%$ of the land area is mountainous and provides water resources to the remaining $30 \%$, where agricultural, industrial and urban activities are carried out. Projection of the impact of climate change on water resources at the local level would provide useful information to decision makers formulating policies for climate change adaptation. In particular, low flow is strongly related to the occurrence of drought, and thus the accurate estimation of low flow is very important for evaluating the impact of climate change on water resources.

Low flow from basins has been studied for more than 100 years because of the significant role of water in human activities. On the basis of the review paper of low-flow studies in the early work presented by Hall (1968), the nonlinearity of low flow in terms of storage volume in the basin was suggested by Horton (1936) and others to satisfy the following exponential function:

$$
Q=K S^{N}
$$

where $Q$ is the discharge, $S$ is the storage, $K$ is a constant and $N$ is the exponential value. This equation is often used in developing recession analysis, estimating low flow, and modelling hydrological processes (e.g. Wittenberg 1994, Tallaksen 1995, Ress et al. 2004). However, in the mathematical approach, the groundwater runoff was divided into unconfined and confined aquifers by Ding (1965), and the groundwater runoff from unconfined aquifers is expressed as the following quadratic exponential equation:

$$
Q=K^{2} S^{2}
$$

Equation (2) has been used for groundwater estimation in the daily hydrological modelling of urban hilly, natural hilly and mountainous basins (Ando et al. 1983, 1984, Ando 1989). Fujimura et al. (2012) developed this daily hydrological model into an hourly hydrological model based on the Diskin-Nazimov infiltration model and the storage function method for the direct runoff for a mountainous basin and applied it to the SAME basin. However, increasingly accurate estimation of reservoir inflow is required. In a recent study, Ding (2011) approximated the storage-discharge relationship of equation (2) as the following general equation: 


$$
Q=K^{N} S^{N}
$$

Although Ding used the generalized storage-discharge relationship of equation (3) for a short-term runoff event of less than 14 hours using the instantaneous unit hydrograph method, equation (3) was not yet used for a long-term runoff event including the low flow. Since the constant $K$ is defined as the fractional recession constant and symbolized as $A u$ by Ando et al. (e.g., 1983), in this study, we rewrite equation (3) as follows:

$$
Q g=A u^{N} S g^{N}
$$

where $Q g$ is the groundwater runoff and $S g$ is the groundwater storage. The purpose of this study is to apply the storage-discharge equation of the low flow, equations (3) and (4), to the hourly hydrological model for a long-term period, and identify the properties of the two parameters in equation (4) of the constant $A u$ and exponent value $N$ by sensitivity analysis. The study basins are different in climatic and geological conditions.

\section{MATERIALS AND METHODS}

\section{Study area}

To examine the low-flow parameters $A u$ and $N$ in equation (4), we selected two mountainous basins with very different climatic and geological conditions. One is the Sameura Dam basin (SAME basin) located in the Shikoku mountains in western Japan, and the other the Shirakawa Dam basin (SIRA basin), located in the Iide mountains in the Tohoku region in eastern Japan. The locations of the basins are shown in Fig. 1. The SAME basin is the upriver basin of the Yoshino River basin and has a basin area of $472 \mathrm{~km}^{2}$. Its elevation ranges from 324 to $1880 \mathrm{~m}$ a.s.l. and the average elevation is $910 \mathrm{~m}$ a.s.l. Water resources for agricultural, industrial and urban use, as well as household water supply for the four prefectures on the island of Shikoku (Kochi, Ehime,

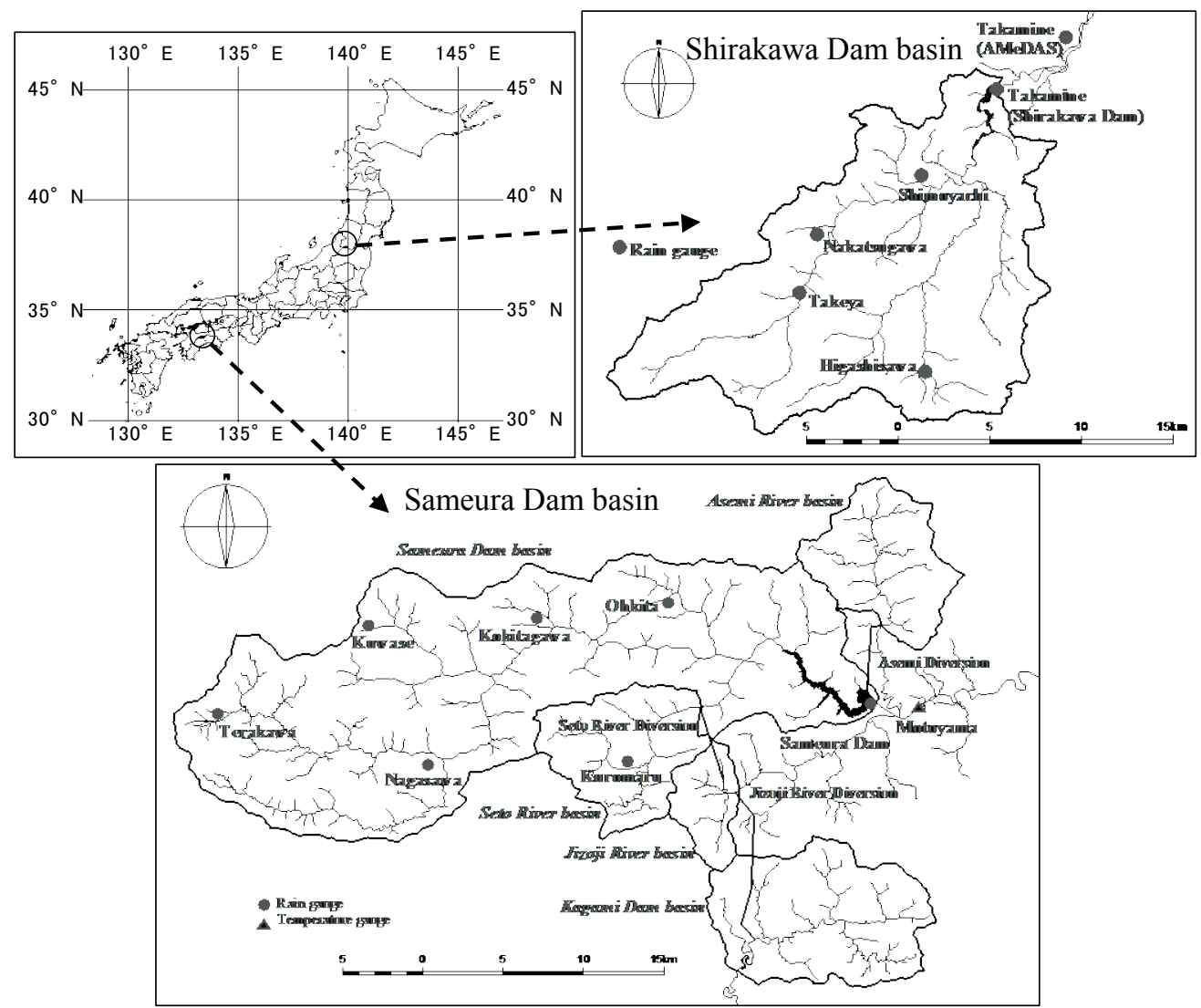

Fig. 1 Maps of the Sameura Dam basin (SAME basin) in the Shikoku region and the Shirakawa Dam basin (SIRA basin) in the Tohoku region. 

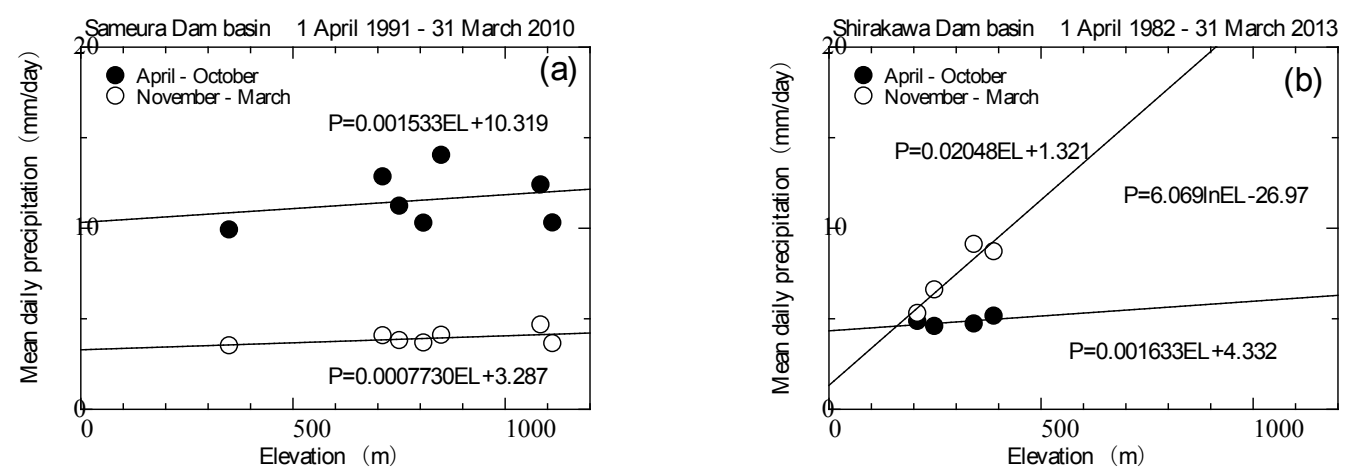

Fig. 2 Seasonal relationship between mean daily precipitation and elevation for the SAME basin (a) and for the SIRA basin (b).

Tokushima and Kagawa), are dependent on Sameura Dam. In particular the low flow of the Seto River in the basin is diverted to supply municipal and industrial (M\&I) water to the Kochi City via two tunnels: the Seto River Diversion and the Jizoji River Diversion. The SIRA basin is the upstream basin of the Mogami River, which is in a region of heavy snowfall in Japan, and has a basin area of $205 \mathrm{~km}^{2}$. Its elevation ranges from 321 to $2029 \mathrm{~m}$ a.s.l. with the average elevation being $697 \mathrm{~m}$ a.s.l. The water stored in Shirakawa Dam is mainly used in rice fields.

The rainfall data measured by the Ministry of Land, Infrastructure and Transport and the Automated Meteorological Data Acquisition System (AMeDAS) of Japan Meteorological Agency are used. Figure 2 shows the seasonal relationship between precipitation and elevation of the two basins using the available AMeDAS data. The SAME basin has much precipitation in the spring / summer season (from April to October) because of typhoons rather than the autumn / winter season (from November to March), whereas the SIRA basin has a strong relationship between precipitation and elevation in the autumn / winter season because of heavy snowfall in the winter season rather than the spring / summer season. These relationships between precipitation and elevation were used in the hydrological analysis. The period of available hydrological data is 20 years from 1 January 1991 to 31 December 2010 for the SAME basin and 10 years from 1 October 2003 to 30 September 2013 for the SIRA basin.

\section{Hydrological model}

The schematic structure of the hourly hydrological model is shown in Fig. 3. The model comprises approximately three components: the Diskin-Nazimov rainfall infiltration model (Diskin and Nazimov, 1995, 1996), groundwater recharge and groundwater runoff calculations, and a direct runoff component that represents surface water storage within the basin. The output from each reservoir element can be described by a linear function or a nonlinear function. The basin was divided into a $500 \mathrm{~m}$ mesh, and at each grid the rainfall was estimated by an inverse distance weighting method using the seven rainfall gauges in the basin. Also at each grid, the infiltration rate and then the excess rainfall were calculated. The parameters except $A u$ and $N$ were calibrated and measured by Fujimura and Ando (2001) and Fujimura et al. (2012).

\section{RESULTS}

\section{Sensitivity analysis}

Since the two parameters, the fractional recession constant $A u$ and the exponent value $N$, are determined by trial-and-error, uncertainty remains in these parameters. To evaluate these two parameters for low flow, sensitivity analysis was carried out. In the analysis, the $A u$ value ranges from 0.0001 to 0.0100 in steps of 0.0001 (a total of 100 steps), and the $N$ value ranges from 1.0 to 100.0 in steps of 0.5 (a total of 199 steps). Therefore, the total number of simulations was 19900 (100 times 199) for each basin. One simulation for the 20 year period of the SAME basin and 10 year period of the SIRA basin took approx. 0.82 minutes and 0.27 minutes, respectively, on a 


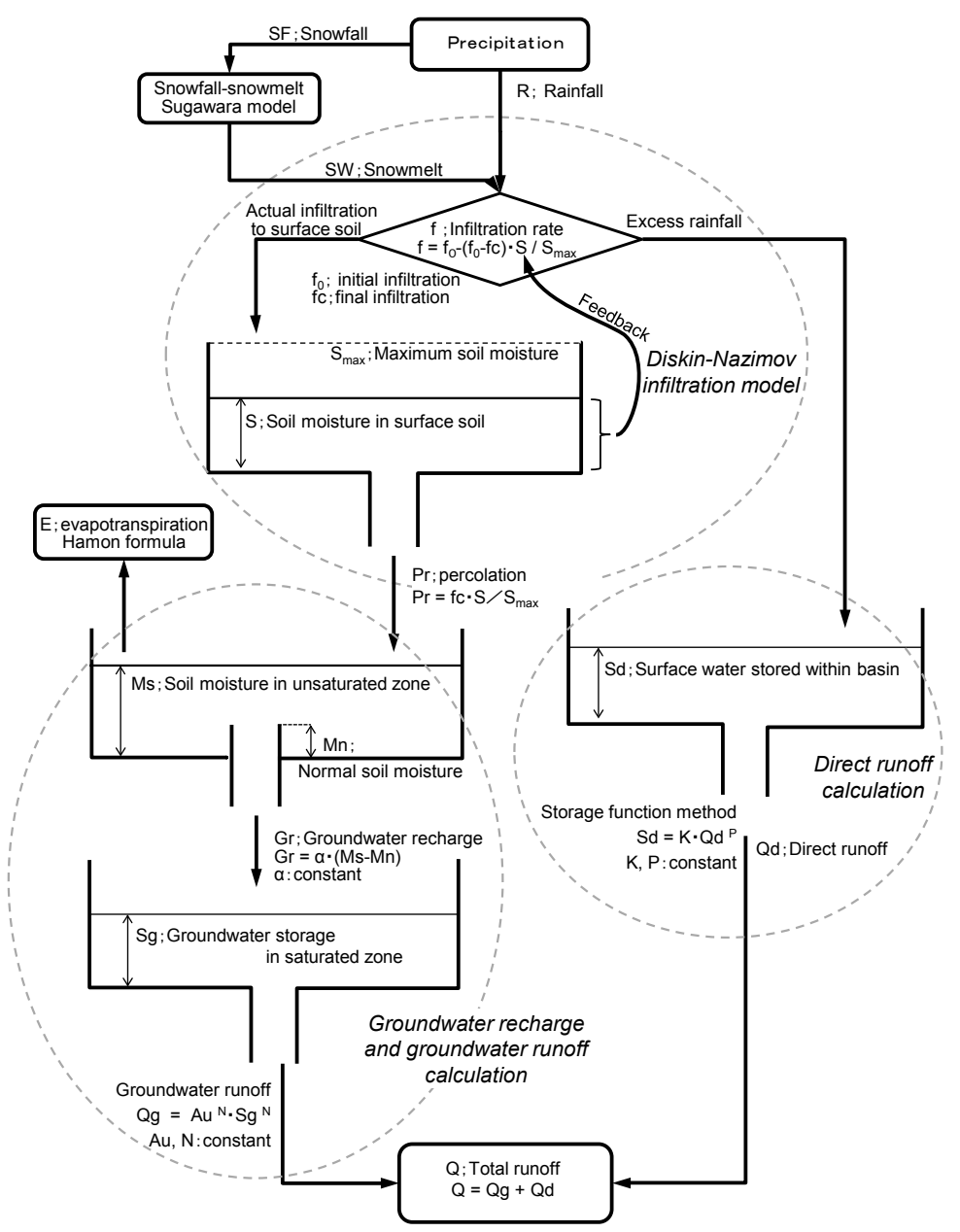

Fig. 3 Simplified schematic of the hourly hydrological model.

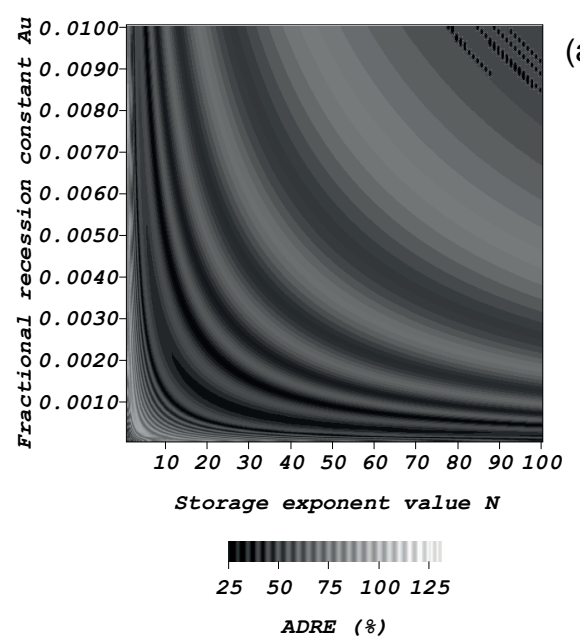

(a)

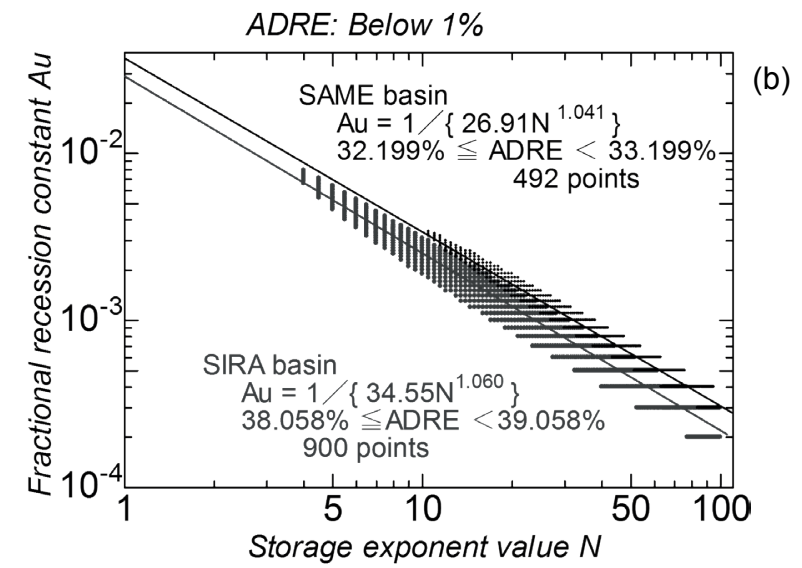

Fig. 4 (a) Visualized $A D R E$ of the SIRA basin and (b) lower 1\% values of the $A D R E$ and identified $A u$ $N$ exponential equations for the two basins.

computer with an Intel ${ }^{\circledR}$ Core ${ }^{\mathrm{TM}}$ i7-3820 processor at $3.60 \mathrm{GHz}$. Each simulation and the two parameters were assessed using the Average Daily runoff Relative Error $(A D R E)$ as the following:

$$
A D R E=\frac{1}{n} \times \sum\left(\frac{\left|Q_{c d}-Q_{o d}\right|}{Q_{o d}} \times 100\right)
$$


where $Q_{c d}$ is the calculated mean daily total runoff, $Q_{o d}$ it the observed mean daily total runoff and $n$ is the number of evaluated observations. In this study, the $A D R E$ focused on low flow with the observed runoff values from 0.4 to $10 \mathrm{~mm}$ /day.

The results of this sensitivity analysis with respect to the relationship between $A u$ and $N$ are shown in Fig. 4. For example, for the SIRA basin, the visualized ADRE is shown as contours in Fig. 4(a), in which the plots of the lower values of the $A D R E$ is shown as the central contour in the graph. For both basins, the plots of the lower (lower 1\%) values of the ADRE are shown in Fig. 4 (b). The plots of the lower $1 \%$ values of the $A D R E$ for the SAME basin overlap those for the SIRA basin. The relationship between $A u$ and $N$ is formulated as the following exponential equations;

$$
A u=\frac{1}{26.91 N^{1.041}} \quad(\text { SAME basin }) \quad \text { and } \quad A u=\frac{1}{34.55 N^{1.060}} \quad(\text { SIRA basin })
$$

The combinations of $A u$ and $N$ that yield the lower values of the $A D R E$ are identified by the exponential equations, such as equation (6). The values of the constants in each equation are similar, despite the different natural conditions of each basin. It is considered that when $N$ values higher than 10 are input into the exponential equation and $A u$ values obtained, hydrological analysis can be performed within the satisfaction situation. Furthermore, the relationship between groundwater storage and groundwater runoff (discharge) exhibits strong nonlinearity because the $N$ values are considered to exceed 10 . The minimum value of the $A D R E$ is $32.196 \%$ using $N=$ 100.0 and $A u=0.0003$ for the SAME basin, and $38.058 \%$ using $N=70.0$ and $A u=0.0003$ for the SIRA basin. The minimum ADRE values are not low; it is higher than $30 \%$ for both basins, which seems the effect of the turbulence of the observed hydrograph. An example of the simulated mean daily hydrograph for the SIRA basin using optimal parameters is shown in Fig. 5.

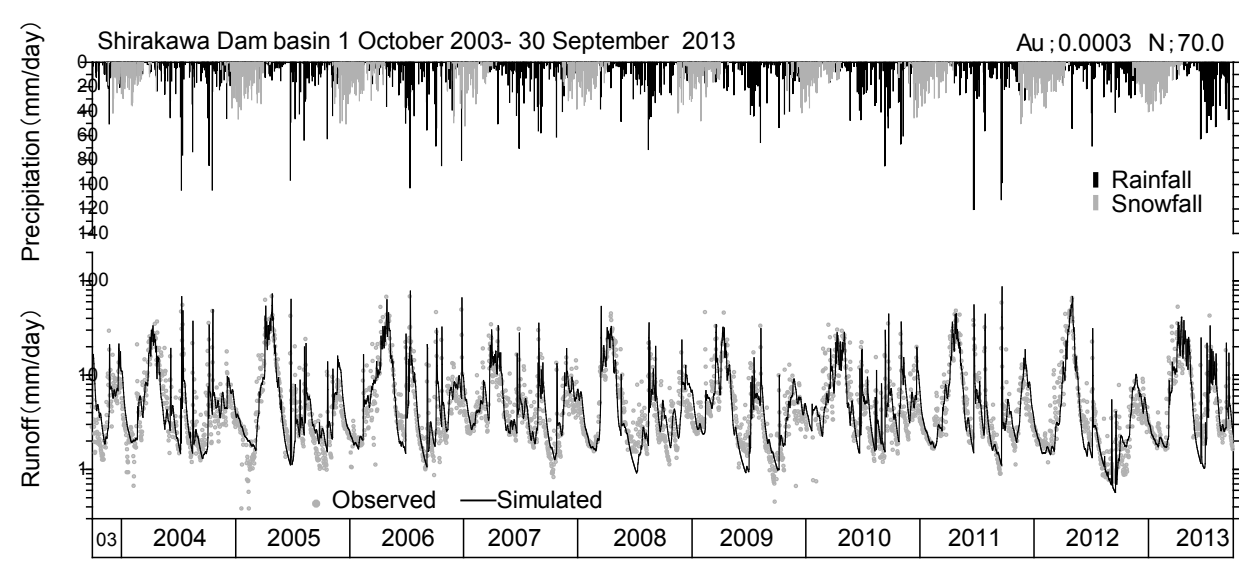

Fig. 5 An example of simulated mean daily hydrograph for the SIRA basin using the optimized parameters of $A u=0.0003$ and $N=70.0$.
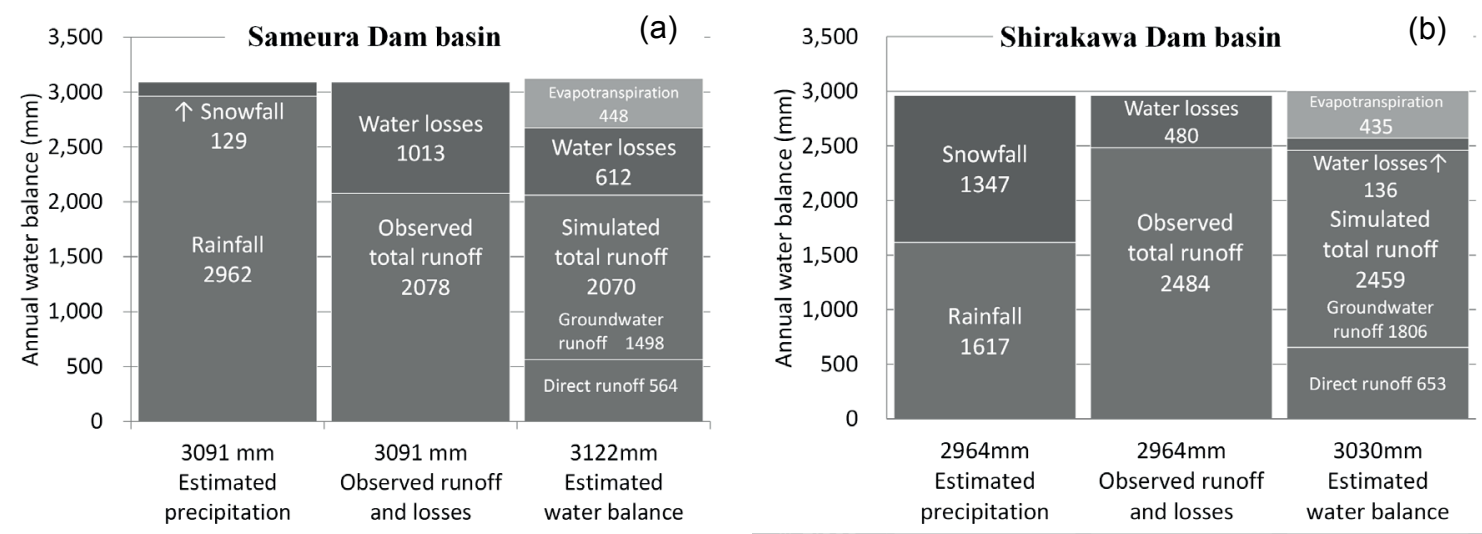

Fig. 6 Annual water balance for the SAME basin (a) and for the SIRA basin (b). 


\section{Annual water balance}

The annual water balances have been estimated by hydrological analysis using the optimal parameters of low flow. The SAME basin experiences some heavy rainfall events in the summer season, e.g. typhoons, whereas the SIRA basin is subjected to heavy snowfall in the winter season, as indicated by the precipitation in Fig. 6(a),(b). Geologically, Mesozoic and Palaeozoic formations are found in the SAME basin, and Quaternary, and Tertiary Quaternary volcanic rock formations are found in the SIRA basin. Low flows are classified according to the basin geology (Musiake et al. 1975); the recession curves are gentle for Quaternary/Tertiary Quaternary volcanic rock basins and steep for Mesozoic/Palaeozoic formation basins. These are indicated in annual water balances in Fig. 6(a),(b), where the SIRA basin has much greater groundwater runoff than the SAME basin.

\section{CONCLUSIONS}

In this study, the two parameters of the storage-discharge equation for low flow, that is the constant $A u$ and the exponent value $N$, were identified and formulated using the exponential equation on the basis of the results of sensitivity analysis using the hourly hydrological model. The optimal sets of $A u$ and $N$, which yield the lowest relative error in the hydrological analysis, are expressed in the exponent function of $A u$ and $N$. The optimal value of exponent $N$ appears as higher than 10 in this study, which suggests low flow has high nonlinearity because low flow is the cumulative hydrological phenomenon in a wide basin scale for a long time period.

Acknowledgements The authors wish to express their sincere gratitude to Ikeda Dam Control and Management Office of Japan Water Agency for providing rainfall and dam inflow data. This work was supported by the Research Program on Climate Change Adaption (the RECCA Project) of the Ministry of Education, Culture, Sports, Science and Technology.

\section{REFERENCES}

Ando, Y. (1989) Modelling of hydrological processes for a mountainous basin. In: New Directions for Surface Water Modeling (ed. by M. L. Kavvas) IAHS Publ. 181, 143-147. IAHS Press, Wallingford, UK.

Ando, Y., Musiake, K. and Takahasi, Y. (1983) Modelling of hydrologic processes in a small natural hillslope basin, based on the synthesis of partial hydrological relationships. Journal of Hydrology 64, 311-337.

Ando, Y., Musiake, K. and Takahasi, Y. (1984) Modelling of hydrologic processes in a small urbanized hillslope basin with comments on the effect of urbanization. Journal of Hydrology 68, 61-83.

Diskin, M. H. and Nazimov, N. (1995) Linear reservoir with feedback regulated inlet as a model for the infiltration process. Journal of Hydrology 172, 313-330.

Diskin, M. H. and Nazimov, N. (1996) Ponding time and infiltration capacity variation during steady rainfall. Journal of Hydrology 178, 369-380.

Ding, J. Y. (1965) Discussion of "Inflow hydrographs from large unconfined aquifers" by Ibrahim, H. A. and Brutsaert, W., J. Irrig. Drain. Div., ASCE 92 (IR1), 104-107.

Ding, J. Y. (2011) A measure of watershed nonlinearity: interpreting a variable instantaneous unit hydrograph model on two vastly different sized watersheds. Hydrol. Earth Syst. Sci. 15, 405-423.

Fujimura, K. and Ando, Y. (2001) Analysis of infiltration capacity in upper soil layer during unsteady rainfall using a rainfall simulator. In: Urban Drainage Modeling (ed. By R. W. Brashear and C. Maksimovic), ASCE, 83-88.

Fujimura, K., et al. (2012) Development of the hourly hydrological model for mountainous basins using the storage function method and the Diskin-Nazimov infiltration model. In: Models - Repositories of Knowledge, IAHS Publ. 355, 338-344. IAHS Press, Wallingford, UK.

Hall, F. R. (1968) Base flow recessions - a review. Water Resour. Res. 4(5), 973-983.

Horton, R. E. (1936) Natural stream channel-storage. Trans. Am. Geophys. Union 17, 406-415. (Cite by Hall (1968).)

Musiake, K., Inokuti, S. and Takahasi, Y. (1975) Dependence of low flow characteristics on basin geology in mountainous areas of Japan. In: The Hydrological Characteristics of River Basins. IAHS Publ. 117, 147-156. IAHS Press, Wallingford, UK.

Rees, H., et al. (2004) Recession-based hydrological models for estimating low flows in ungauged catchments in the Himalayas. Hydrol. Earth Syst. Sci. 8(5), 891-902.

Smakhtin, V. U. (2001) Low flow hydrology: a review. Journal of Hydrology, 240, 147-186.

Tallaksen, L. M. (1995) A review of baseflow recession analysis. Journal of Hydrology 165, 349-370.

Wittenberg, H. (1994) Nonlinear analysis of flow recession curves. In: FRIEND-Flow Regimes from International Experimental and Network Data (ed. by P. Seuna et al.) IAHS Publ. 221, 61-67. IAHS Press, Wallingford, UK. 